\title{
Cranberry Fruitworm Acrobasis vaccinii Riley (Lepidoptera: Pyralidae) ${ }^{1}$
}

\author{
James T. Brown and Jennifer L. Gillett-Kaufman²
}

\section{Introduction}

The cranberry fruitworm (Acrobasis vaccinii Riley) (Figure 1 ) is native to North America and has been classified as a pest of cranberry agricultural systems (Tomlinson 1960). As larvae, these insects are the primary pest of large fruit cranberries and a significant pest of highbush blueberries (Fitzpatrick 2008).

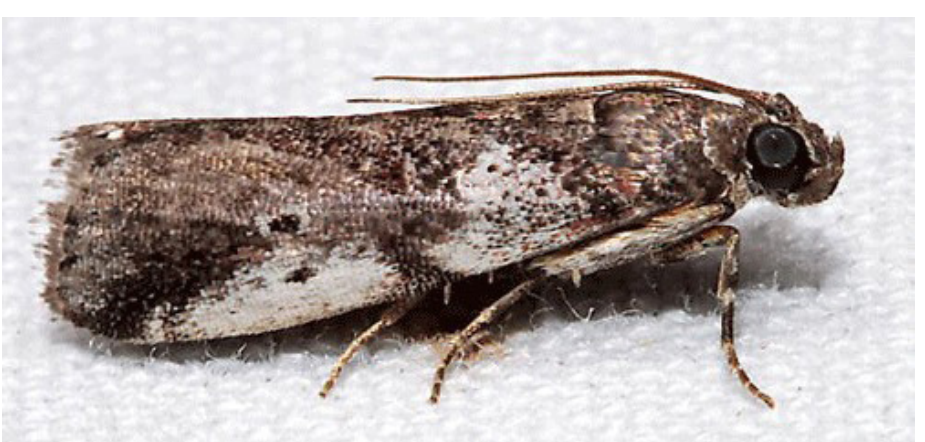

Figure 1. Adult male cranberry fruitworm, Acrobasis vaccinii Riley (lateral view).

Credits: Ken Childs, BugGuide.net

\section{Distribution}

The cranberry fruitworm has been found across eastern North America from Florida to Nova Scotia and westward to Wisconsin and Texas (Averill and Sylvia 1998, Murray et al. 1996, Cee and Liburd 1993, Neunzig 1972). Crowley (1954) reported small populations of the cranberry fruitworm in the Pacific Northwest, where it continues to persist.

\section{Description and Life Cycle}

The life cycle of the cranberry fruitworm is synchronized with the seasonal availability of its host fruit. At the northern boundary of the cranberry fruitworm population distribution (the northeastern United States and southern parts of Canada) the growing season for cranberry fruitworm host plants is shorter and cranberry fruitworm only produces a single generation of successful larvae before the onset of winter (Figure 2). When the warm summer growing season ends, larvae exit the fruit and overwinter in the leaf litter at the base of the host plant. Before entering diapause, larvae protect themselves from exposure and predation by creating a silk hibernaculum (cocoon) in which to diapause throughout winter. In the spring of the following year, larvae terminate diapause and pupate. Adults emerge shortly thereafter to find mates and produce the next generation of cranberry fruitworms (Neunzig 1972).

Adult cranberry fruitworms mate on the developing host fruit, and females lay their eggs at the calyx end of the berry (part of the fruits farthest from the stem) (Neunzig 1972). First instar larvae hatch out of the eggs and crawl to the stem end of the host fruit, chew into the fruit, cover the entry hole with silk, and feed on the pulp and seeds (Fitzpatrick 2008, Neunzig 1972). Once all the pulp of one berry is consumed, larvae crawl out of the first berry and into an adjacent berry, leaving behind a web of silk and frass as they feed on the berry clusters until larval development is

1. This document is EENY-759, one of a series of the Entomology and Nematology Department, UF/IFAS Extension. Original publication date September 2020. Visit the EDIS website at https://edis.ifas.ufl.edu for the currently supported version of this publication. This document is also available on the Featured Creatures website at http://entomology.ifas.ufl.edu/creatures.

2. James T. Brown and Jennifer L. Gillett-Kaufman, Extension scientist, Entomology and Nematology Department; UF/IFAS Extension, Gainesville, FL 32611.

The Institute of Food and Agricultural Sciences (IFAS) is an Equal Opportunity Institution authorized to provide research, educational information and other services

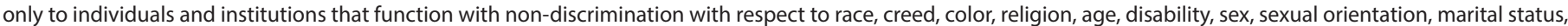

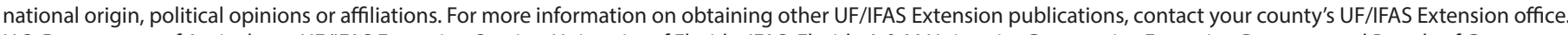
U.S. Department of Agriculture, UF/IFAS Extension Service, University of Florida, IFAS, Florida A \& M University Cooperative Extension Program, and Boards of County Commissioners Cooperating. Nick T. Place, dean for UF/IFAS Extension. 


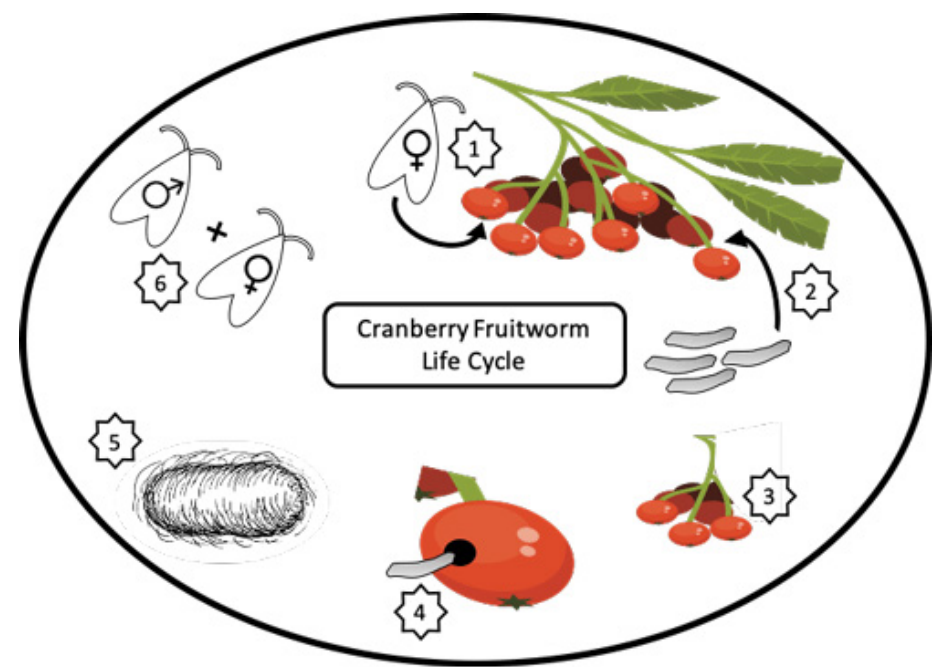

Figure 2. Diagram of the cranberry fruitworm, Acrobasis vaccinii Riley, life history. 1) Female lays eggs at the bottom (calyx) end of the fruit. 2) Larvae hatch and enter the fruit at the stem end. 3) Larvae consume 3 to 8 berries during development. 4) Larvae exit host fruit and form a hibernaculum (cocoon). 5) Larvae pupate inside the cocoon. 6) Adult moths emerge and find mates.

Credits: James T. Brown, University of Florida

complete or the growing season ends. Larvae that do not reach the sixth instar generally do not enter diapause or survive the winter months.

\section{Eggs}

Cranberry fruitworm eggs are flat, white, and resemble scales with a yellow or reddish tinge near the center. Similar to other insects, the development rate of the cranberry fruitworm is affected by temperature. For example, eggs stored at $25^{\circ} \mathrm{C}$ hatch in approximately five days, while eggs stored at $20^{\circ} \mathrm{C}$ hatch after nine days (Averill and Sylvia 1998). After larvae hatch from the eggs, the empty eggs have a brighter appearance and are whiter then eggs that have not hatched (Attaway 2011).

\section{Larvae}

At the most northern edge of the cranberry fruitworm population distribution, the first instar lasts approximately one day, the second instar lasts from two to five days, the third and fourth instars each lasts for nine days, the fifth instar lasts about 16 days, and during the sixth instar the cranberry fruitworm larvae enter larval diapause (Averill and Sylvia 1998). At latitudes farther south of the northern edge of the population range, where growing seasons are longer, larvae have been reported at the start and in the middle of the fruit growing season, which suggests that cranberry fruitworms can produce more than one generation in a single season in warmer regions like Florida (Neunzig 1972).
The head capsule of sixth instar cranberry fruitworm larvae is pale yellow with brownish-yellow spots (Neunzig 1972). The dorsal (top) side of the thorax is reddish yellow, transitioning laterally to a green color and the dorsal side of the abdomen transitions from red at the anterior (head) to reddish yellow at the posterior (back) (Neunzig 1972). Ventrally (on the underside), the thoracic legs of the larvae are pale yellowish white, and the abdomen shifts from a green color on the anterior end to yellow on the posterior end (Neunzig 1972).

Before pupating, cranberry fruitworm larvae undergo six larval instars. Sixth instar cranberry fruitworm larvae can be identified by abdominal spiracles on segment eight directed up away from the larval body and towards the tail end (dorsocaudad). Frequently, a small brown spot appears at the tail end (caudad) or along the sides (subdorsal) of the prothoracic shield (Neunzig 1972). The direction of the spiracles on abdominal segment eight is a physiological adaptation to living inside the pulp of host fruit and allows the larvae to respire in very moist conditions without drowning (Neunzig 1972).

\section{Pupae}

The cranberry fruitworm pupa is yellow brown in color and tends to be darker dorsally. The anterior (head) end of the pupa is slightly wrinkled, and the general body shape is cylindrical (Neunzig 1972). The pupa can also be identified by the lack of punctures along the posterior (tail) end of the pupa (Neunzig 1972). The pupal stage generally lasts 29 days.

\section{Adults}

The undersides of the adult male forewings are white and pale gray with yellow scaling. The upper sides of the male forewings have considerably more white scales at the costa than the undersides of the forewing. The upper side also has a black line along the middle of the wing, a black, almost triangular spot in the middle of the costal region, and diffuse red shading (Figure 1). The adult stage of the Acrobasis Zeller genus is notoriously difficult to identify to species, and within many species, male and female adults have a similar appearance. Forbes (1923) suggests relying on finding the insect on the host plant.

\section{Hosts}

The host range of cranberry fruitworms is limited to berry-producing plants in the genus Gaylussacia, which includes black huckleberry (Gaylussacia baccata (Wangenh.) K. Koch) and plants in the genus Vaccinium, which 
includes which includes large fruit cranberry (Vaccinium macrocarpon Aiton) and highbush blueberry (Vaccinium spp. L.) (Averill and Sylvia 1998). Adults do not feed or cause damage to host fruit; however, females oviposit on the surface of these host fruits, and larvae exclusively feed inside the fruit while it develops.

\section{Economic Importance}

Although females only lay one egg per fruit, a single female can lay up to 50 eggs, and each larva can eat three to eight berries in a single growing season (Mallampalli and Isaacs 2002, Averill and Sylvia 1998, Fitzpatrick and Dokkumburg 2014). Larva feed exclusively inside the fruit, and a single larvae can destroy an entire cluster of berries, leaving behind dried fruit filled with frass and covered in silk webbing (Figure 3).

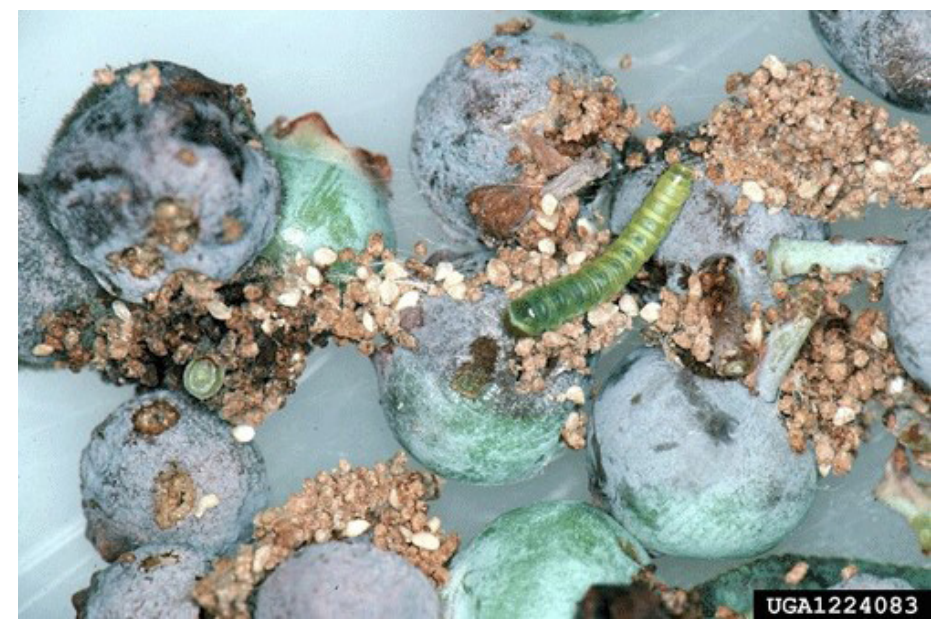

Figure 3. Cranberry fruitworm, Acrobasis vaccinii Riley, larva feeding on a cluster of rabbit-eye blueberry fruit (Vaccinium virgatum Ait.) (dorsal view).

Credits: Jerry A. Payne, USDA Agricultural Research Service, Bugwood. org

At market, the detection of more than one cranberry fruitworm larva in four pints of blueberries sampled from a single pallet is enough to reject that entire pallet (Mallampalli and Isaacs 2002). The financial risk presented by such a low detection threshold has driven the use of pest management strategies that rely on routine insecticide application in response to adult moth capture in permanently placed pheromone traps (Mallampalli and Isaacs 2002). To minimize profit loss, growers monitor their fields during the growing season for cranberry fruitworm activity. Adult moths can be identified by examining diagnostic markings on the forewings (mentioned above in the Description section).

\section{Management}

The cranberry fruitworm is the primary pest of cranberry and is an important pest of blueberries in the eastern US. Most commercial blueberry and cranberry growers rely on routine applications of insecticides to protect their crops until the fruit is harvested for the market. At the beginning of the season, cranberry growers that have experienced high fruitworm pressure in previous years will make an insecticide application once $50 \%$ of the cranberry crop has flowered, then again 10 days later (Averill and Sylvia 2004). Throughout the season, cranberry growers and blueberry growers scout and use pheromone traps to monitor cranberry fruitworm pressure and use additional pesticide applications significantly reduce pest populations (Averill and Sylvia 2004, DeMoranville et al. 2005). By eliminating leaf litter from blueberry systems and artificially flooding cranberry beds in the spring growers can significantly reduce cranberry fruitworm pressure (Attaway 2011, Averill and Sylvia 2004).

Cranberry fruitworm eggs, larvae, and pupae are also susceptible to various parasitic insects. Murray et al. (1996) reported a complex of 17 parasitoid species that used cranberry fruitworm as a host. Wasps in the genus Trichogramma were the most common egg parasitoid. These wasps are generalist parasites whose offspring develop inside cranberry fruitworm eggs (polyphagous endoparasitoid). As the wasp larva develops inside the cranberry fruitworm egg, the moth egg darkens in color. Cranberry fruitworm larvae are most commonly parasitized by the ichneumonid wasp Campoletis patsuiketorum (Viereck). Campoletis patsuiketorum wasps are endoparasitoids of many Lepidopterans. The wasp larva can infest the larval stage of the cranberry fruitworm, consuming the fruitworm's internal tissues until the wasp larva emerges from the fruitworm larva to pupate. Cranberry fruitworm pupae collected from a field site in Michigan were parasitized by the bee fly Villa lateralis (Say) (Murray et. al 1996). Other parasites of cranberry fruitworm eggs, larvae, and pupae are not known. 


\section{Selected References}

Attaway D. 2011. Cranberry Fruitworm. Louisiana State University, Baton Rouge LA. https://www.lsuagcenter. com/topics/crops/fruits_and_vegetables/blueberries/pests/ cranberryfruitworm (14 Sept 2019).

Averill AL, Sylvia MM. 1998. Cranberry Insects of the Northeast: A Guide to Identification Biology and Management. Department of Entomology and Cranberry Station, University of Massachusetts at Amherst 46-51.

Averill AL, Sylvia MM. 2004. Insect Management. In: Sylvia MM, Cannon D. (Eds.) Cranberry chart book 2018-2020 management guide for Massachusetts. University of Massachusetts at Amhurst Cranberry Station Publication. 28-30 pp. (10 March 2020).

Cee JL, Liburd OE. 2007. Insect management in blueberries in the eastern United States. 2007: 5 pp. (13 April 2019).

DeMoranville C, Sandler H, Shumaker D, Averill A, Caruso F, Sylvia M, Pober D. 2005. "Fall flooding for management of cranberry fruitworm (Acrobasis vaccinii) and dewberry (Rubus hispidus) in Massachusetts cranberry production." Crop Protection 24: 999-1006.

Fitzpatrick SM. 2009. "Insect life histories in fruit, shoot and root environments of cranberry and blueberry." Acta Horticulturae 810: 231-234.

Fitzpatrick S, van Dokkumburg H, Prasad R. 2014. "BC cranberry insect pest identification guide." BC Cranberry Research Society 17.

Forbes WM. 1923. "Lepidoptera of New York and neighboring states." Cornell University Agriculture Experimental Station Memoir 68: 184-194.

Godin J, Maltais P, Gaudet S. 2002. Head capsule width as an instar indicator for larvae of the cranberry fruitworm (Lepidoptera: Pyralidae) in southeastern New Brunswick. Journal of Economic Entomology 95: 1308-1313.

Mallampalli N, Isaacs R. 2002. "Distribution of egg and larval populations of cranberry fruitworm (Lepidoptera: Pyralidae) and cherry fruitworm (Lepidoptera: Tortricidae) in highbush blueberry." Environmental Entomology 31: 852-858.

Marucci P. 1966. Blueberry Insects and Their Control. Blueberry Culture. P. Eck \& N. F. Childers edition. Rutgers University Press, New Brunswick NJ. pp. 199-235.
Milholland RD, Meyer JR. 1984. Diseases and arthropod pests of blueberries. North Carolina State University Bulletin 468. 33 p.

Murray DA, Kriegel RD, Johnson JW, Howitt AJ. 1996. "Natural enemies of cranberry fruitworm, Acrobasis vaccinii, (Lepidoptera: Pyralidae) in Michigan highbush blueberries." The Great Lakes Entomologist 29: 81-86.

Neunzig HH. 1972. "Taxonomy of larvae and pupae in eastern North America (Lepidoptera: Pyralidae)." USDA ARS Technical Bulletin 1457: 1-18.

Simser D. 1995. "Parasitism of cranberry fruitworm (Acrobasis vaccinii; Lepidoptera: Pyralidae) by endemic or released Trichogramma pretiosum (Hymenoptera: Trichogrammatidae)." The Great Lakes Entomologist 4: 189-196.

Tomlinson WE. 1960. "Control of the cranberry fruitworm, Acrobasis vaccinii." Journal of Economic Entomology 53: 1116-1119. 